\author{
Luka Boban \\ Vladimir Soldo \\ Jure Stošić \\ Eugen Filipović \\ Filip Tremac
}

https://doi.org/10.21278/TOF.42Si104

ISSN 1333-1124

eISSN 1849-1391

\title{
GROUND THERMAL RESPONSE AND RECOVERY AFTER HEAT INJECTION: EXPERIMENTAL INVESTIGATION
}

\begin{abstract}
Summary
Monitoring the ground thermal response to a constant heat flux input is common method for determination of effective ground properties needed for sizing the ground coupled heat pumps. In this work, the experimental procedure included two TRT's with different average injection heat fluxes, $4.43 \mathrm{~kW}$ and $7.64 \mathrm{~kW}$, applied to the same borehole. Recorded temperatures of fluids, circulated in an experimental borehole heat exchanger U-tube, are used to determine the ground thermal conductivity and the borehole thermal resistance with the infinite line source model (ILS). Additionally, thermocouples placed on the borehole wall up to the depth of $100 \mathrm{~m}$ enabled the measurement of temperature profiles of undisturbed ground and during the recovery period between the two TRTs. The results indicate that true undisturbed state after injected heat flux cannot be reached in short time while the use of higher injection heat flux reduces the influence of the ground's inhomogeneity on the results obtained.
\end{abstract}

Key words: $\quad$ borehole heat exchanger, thermal response test, ground thermal properties, borehole thermal resistance

\section{Introduction}

The heat pumps combined with vertical borehole heat exchangers (BHE) are utilizing the ground as a heat source or sink for the purpose of heating or cooling of buildings. The depth of the boreholes usually varies between 60 and $200 \mathrm{~m}$ [1]. The heat exchangers that are placed in a borehole are designed as U-pipes, or as coaxial tubes of different geometry. In Upipe heat exchangers, the complete flow is subjected to heat exchange with the ground, while in coaxial heat exchangers only a part of the flow participates in this process [2].

The heat exchange process, and thus the ground heat pump performance, is highly dependent on the thermal properties of the ground. These properties cannot be influenced and they vary depending on the ground composition, porosity and the presence of groundwater. The properties of interest are, above all, thermal conductivity $\lambda, \mathrm{W} /(\mathrm{m} \cdot \mathrm{K})$ and specific heat capacity $c, \mathrm{~J} /(\mathrm{kg} \cdot \mathrm{K})[3]$. As the ground in most cases possess non-homogeneous structure, the ground thermal conductivity is expressed as effective value for a given location. 
Along with the thermal properties of the ground, the heat exchange process in a BHE is also influenced by its design. Increasing the vertical heat exchanger depth lowers the difference between the average fluid temperature and the ground temperature, for the same amount of heat transferred to or from the ground [4]. The influence of BHE radius is similar to the influence of the heat exchanger depth. Increasing the BHE radius leads to lower temperature difference needed to transfer the same amount of heat. The distance between the heat exchanger pipes as well as the borehole filling material has significant influence on thermal resistance $[5,6]$. For an efficient BHE, it is vital to perform quality grouting procedure, without cavities which act as thermal resistance. All the aforementioned parameters are taken into account with the borehole thermal resistance that can be determined analytically or experimentally $[7,8]$.

Commonly, effective thermal conductivity and borehole thermal resistance are obtained by application of thermal response test on existing borehole heat exchanger [9]. Different mathematical models, both numerical and analytical, can be applied to determine the thermal properties based on the data obtained with TRT measurements. The most widely adopted is Infinite Line Source model (ILS), an analytical model that simplifies BHE with infinite line source theory [10]. More complex models are numerical ones that also include combination of numerical and analytical approaches $[11,12]$.

In this paper, two TRT measurements with different heat power were carried out at premises of Faculty of Mechanical Engineering and Naval Architecture (University of Zagreb) where a $100 \mathrm{~m}$ deep BHE is located. The thermal properties of the ground are determined using ILS model while installed thermocouples enable observation of temperature changes at different depths in the ground during heating and recovery phase. Goal of this research is to analyse the heat flux influence on the resulting effective thermal properties obtained and distributed temperature changes in the underground.

\section{Methodology}

\subsection{Experimental rig}

The experimental rig, used in this study, is composed of the mobile TRT device connected to BHE, thermocouples connected to the acquisition device and a computer for data storage. The thermocouples are arranged around the borehole circumference and placed at different depths on the borehole wall. Such configuration enables distributed temperature measurements along the depth of the borehole. In other studies authors used fiber optic cables placed inside the U-pipe [13], based on works of Acuna [2] and Fujii [14].

The TRT device contains electric heater, circulation pump, and devices for flow rate and temperature measurement (Figure 1). The measurements were carried out using the GEOgert 2.0 unit consisting of two modules capable of conducting pressure test, flow test, undisturbed ground temperature measurement and TRT. It is equipped with two constant $(2 \times 3 \mathrm{~kW})$ and one variable heater $(1.5 \mathrm{~kW})$, PT probes (response time $\leq 10 \mathrm{~s}$; resolution: $<0.01{ }^{\circ} \mathrm{C}$ ) for temperature measurements, pressure sensors (full scale value (FSV): 25 bar, relatives; precision $(\% \mathrm{FSV}): \leq 0.25)$ and electromagnetic flow meter (error $\pm 0.2 \%$ from the measured value $+1 \mathrm{~mm} / \mathrm{s}$ ). According to the probe configuration precision in the measurement of the delivered heat is $1-3 \%$ as stated by manufacturer Geoenergia Srl.

The whole procedure has several steps: At the very beginning, the basic BHE data are entered together with the pipe dimensions, borehole filling density and borehole filling conductivity. Then, the specific parameters are set: flow rate, heating power, examination time duration and the data gathering time interval. The pressure and hydraulic tests are carried out and the undisturbed ground temperature measurement is performed. After the circulation 
pump and the heater are turned on, the heated water circulates through BHE and participates in the process of heat exchange with the ground, while the flow rate, heating power, inlet and outlet water temperatures are measured continuously.
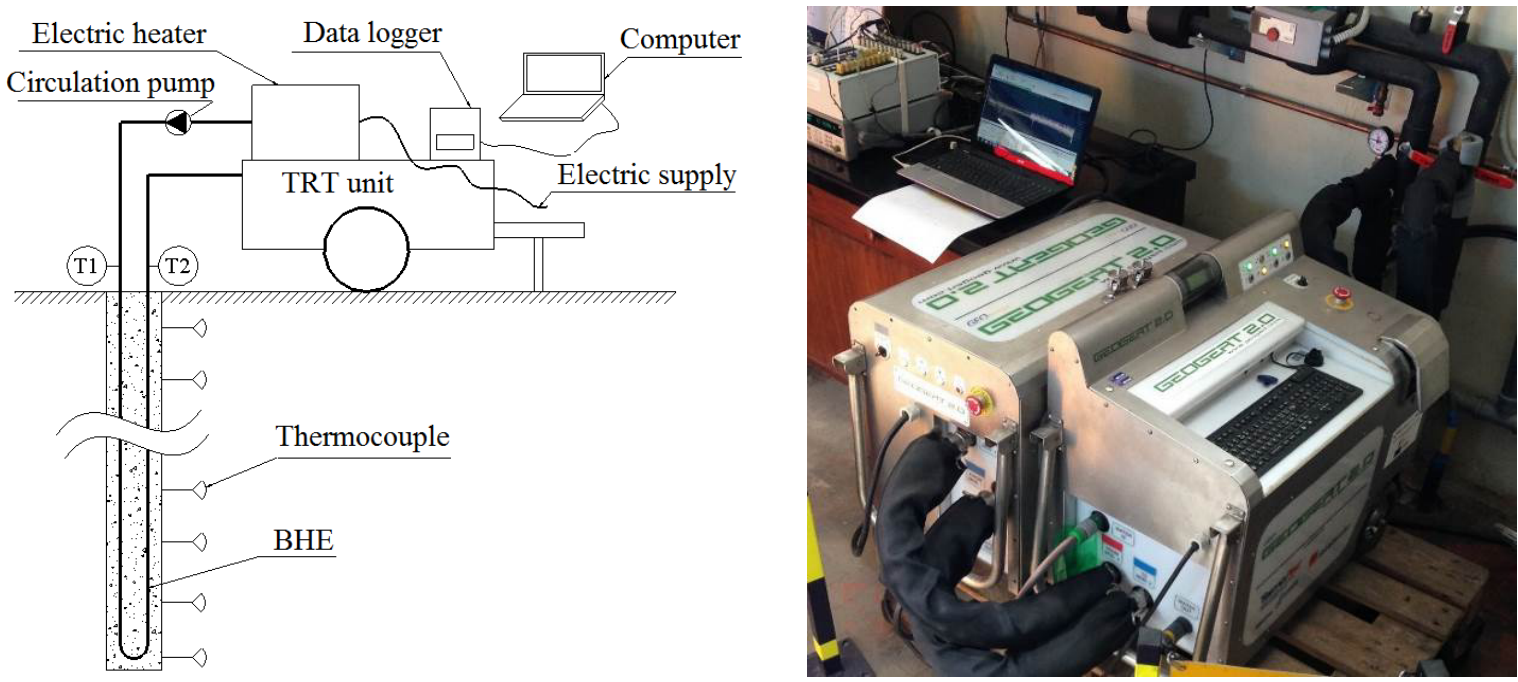

Fig. 1 The experimental rig: schematic display (left) and real device (right)

\subsection{Borehole heat exchanger}

All the measurements were conducted at FMENA, where a $100 \mathrm{~m}$ deep BHE is located. The borehole diameter is $152 \mathrm{~mm}$ wide. In the borehole, a double $U$ pipe heat exchanger with $32 \mathrm{~mm}$ diameter pipes (PE 100, SDR100) is placed. Temperature sensors are installed on the borehole wall to enable temperature measurements at different depths. The borehole is filled with a commercial bentonite and cementite mixture with thermal conductivity of $2.0 \mathrm{~W} /(\mathrm{m} \mathrm{K})$ [15]. Zagreb location is characterized by sedimentary cover with coarser-grained sediments. Soil samples were collected during drilling procedure and resulting profile of horizontal geological layers at the location of FMENA is depicted in Figure 2.

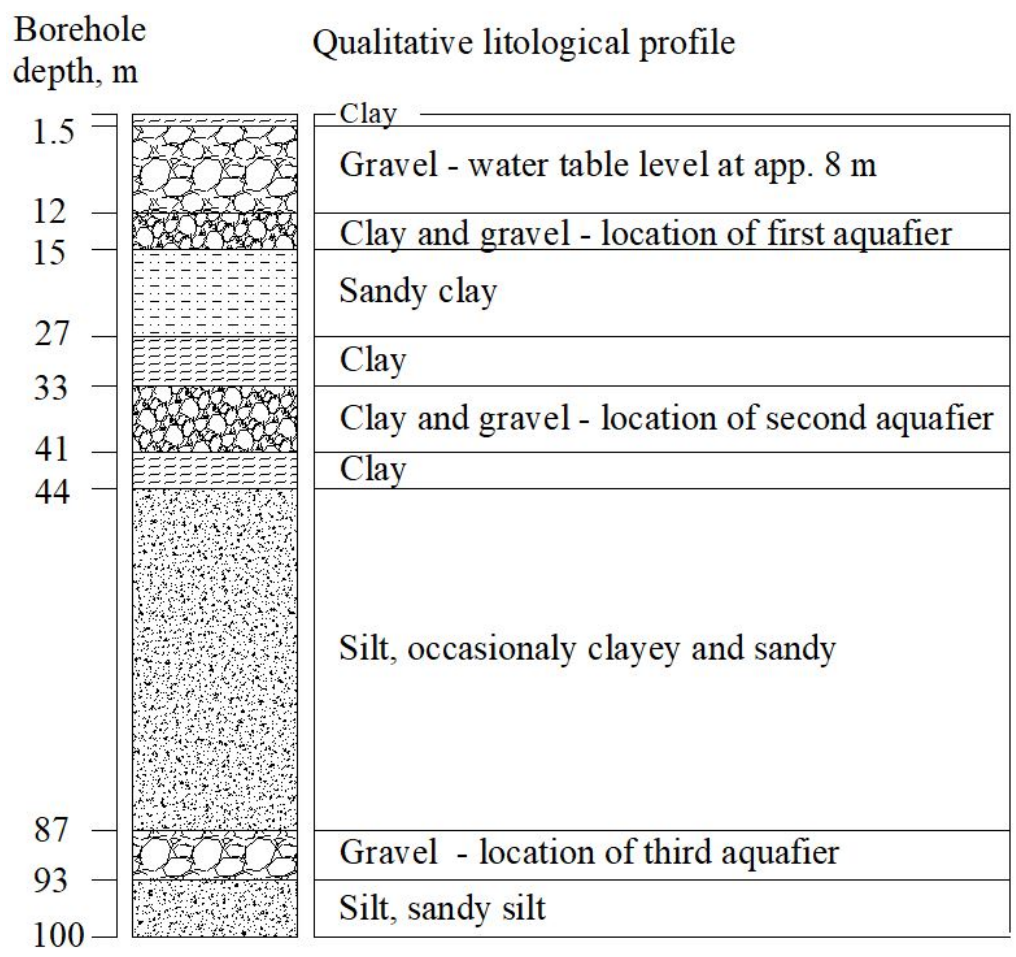

Fig. 2 The lithological profile at the FMENA location 
One can notice the fine gravel in first ten meters of the borehole depth while the ground after $15 \mathrm{~m}$ till $100 \mathrm{~m}$ depth is clay-dominated. Groundwater table is approximately at $8 \mathrm{~m}$ depth. Borehole is located in an aquifer oriented from West to East so advection component in the heat transfer is present in the underground, although the flow velocity for observed location is not known.

\section{Results}

\subsection{Undisturbed ground temperature determination}

The undisturbed ground temperature profile represents the average ground temperature around the BHE with respect to its depth, after the thermal equilibrium between the ground and the environment is established. The undisturbed ground temperature profile is measured by thermocouples located around the borehole perimeter at different borehole depths in range from $1.5 \mathrm{~m}$ to $100 \mathrm{~m}$. In Figure 3, the positioning of thermocouples in the borehole is shown.

The data taken for determination of undisturbed ground temperatures exclude the one measured at first $10 \mathrm{~m}$ of borehole depth, in order to eliminate the influences from surface on the ground temperature. Thus, the average undisturbed ground temperature obtained before the first TRT measurement is $13.97{ }^{\circ} \mathrm{C}$.

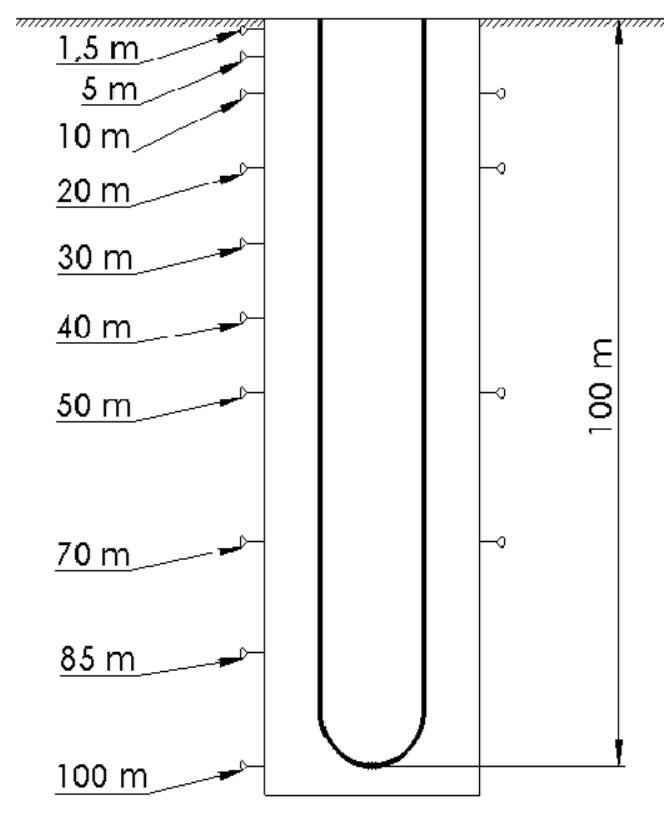

Fig. 3 The thermocouple locations in the borehole

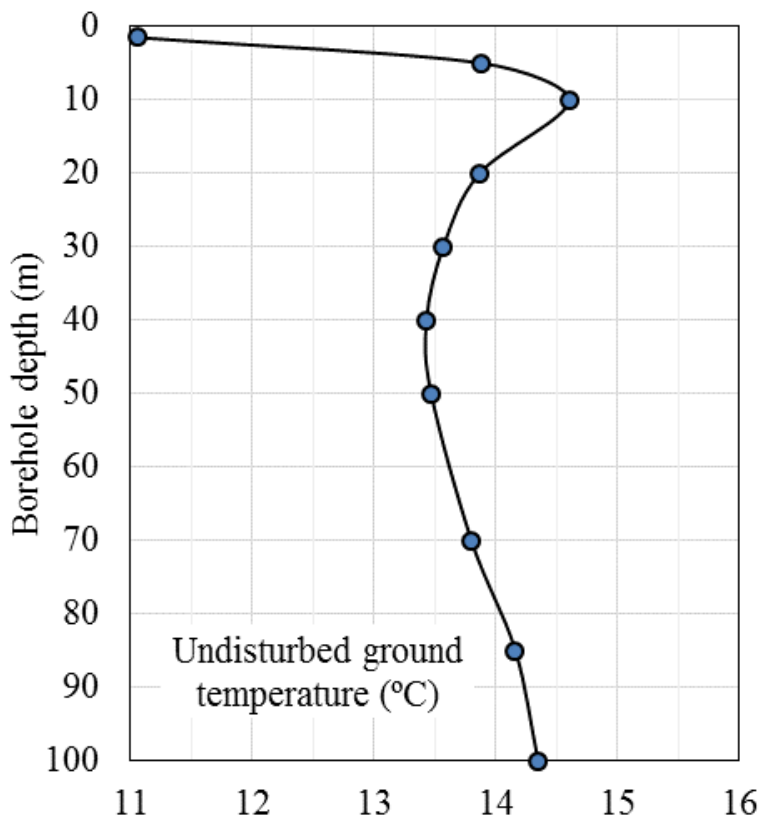

Fig. 4 The undisturbed ground temperature profile (March $19^{\text {th }} 2016$.)

The undisturbed ground temperature profile is shown in Figure 4. The amplitude of seasonal effect decreases with depth and the effect becomes negligible for Zagreb location approximately around $10 \mathrm{~m}$. In the range from 10 to $40 \mathrm{~m}$, the ground temperature is decreasing up to the local minimum which is a profile shape often reported for urban areas [16]. The deviation of the temperature profile from geothermal gradient can be attributed to combined effect of global warming and anthropogenic heat input to the ground [17]. Below $40 \mathrm{~m}$ depth, the temperature rises under the influence of the geothermal gradient. The ground temperature measured at $50 \mathrm{~m}$ is $13.56{ }^{\circ} \mathrm{C}$, while the ground temperature at $100 \mathrm{~m}$ is $14.29{ }^{\circ} \mathrm{C}$. Calculation of geothermal gradient using relatively shallow borehole is not recommended, as the result can be influenced by many uncertainties related to exact position of temperature sensor, aging of thermocouple or remaining thermal disturbances from heat pump operation. 
Temperature profile of lower sections on Figure 4 shows inclination between points that is not continuous, therefore calculation of geothermal gradient using this profile is not recommended. During TRT measurements, the device recirculates the fluid through BHE until the stationary temperature is reached, and records the BHE inlet and outlet temperatures as a function of time. The temperature obtained this way is influenced by the heat gains from the pump and environment.

\subsection{The first TRT measurment}

The first TRT measurement in duration of $72 \mathrm{~h}$ (19.-22. March 2016.) has the following input parameters:

- the average heating power

- the average flow rate

- the average undisturbed ground temperature (thermocouples)
$4.43 \mathrm{~kW}$

$1200 \mathrm{l} / \mathrm{h}$

$13.9{ }^{\circ} \mathrm{C}$

Water is used as a working fluid and fully turbulent flow is maintained $(\mathrm{Re}=6300)$ in both tests. The measurement data (inlet and outlet fluid temperature, flow rate, fluid pressure, electric power of the heater, borehole temperature-depth profiles) is stored with a $60 \mathrm{~s}$ time steps. During the measurements, using the thermocouples and the acquisition device, the change in ground temperature with BHE depth is monitored. Figure 5 shows the temperature changes in time while the constant heat flux of $4.3 \mathrm{~kW}$ is applied.

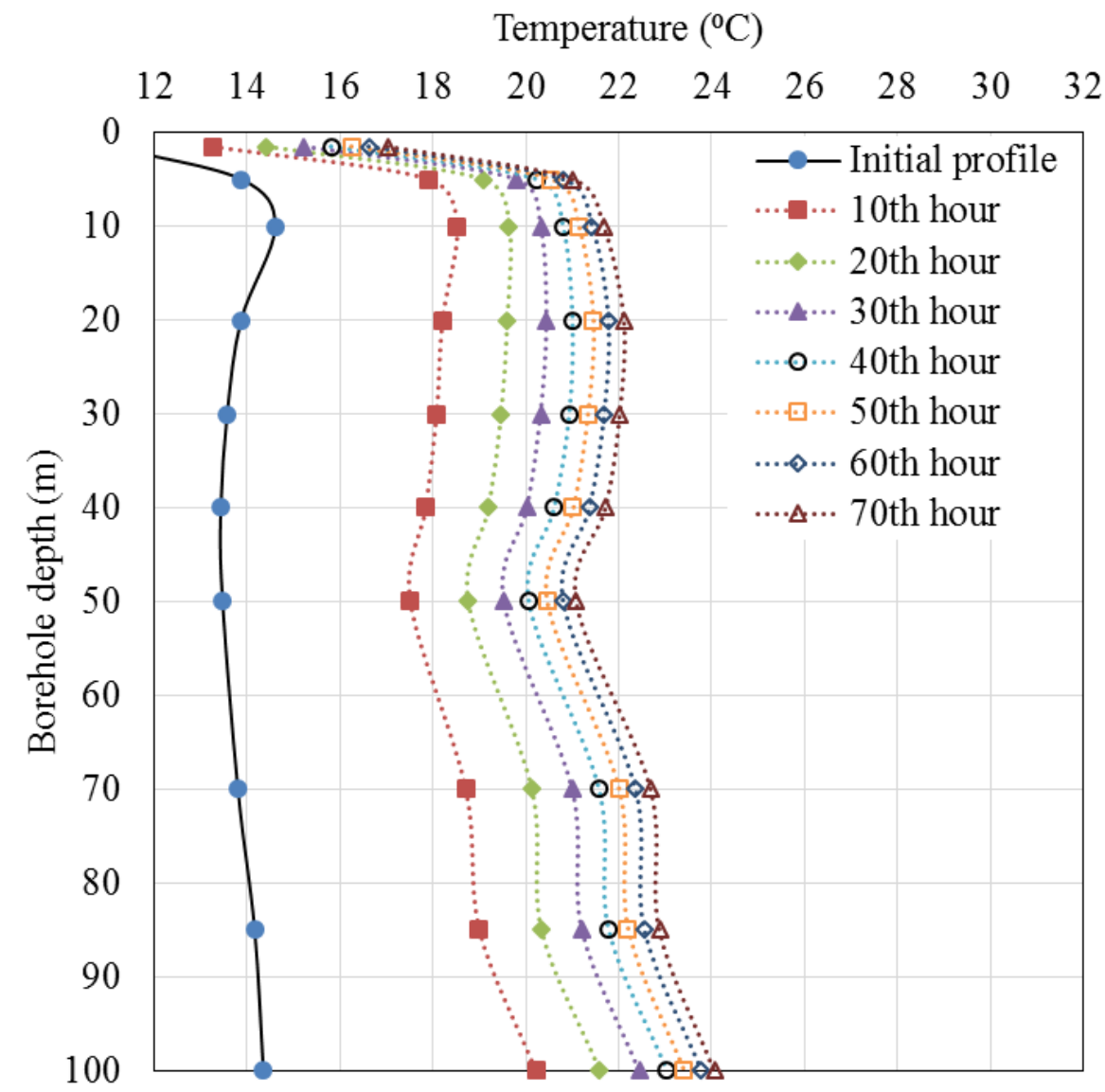

Fig. 5 The ground temperature profiles during the first TRT (4.43 kW) (19.-22. March 2016.)

In Figure 6, a recovery after TRT procedure is shown. The ground thermal properties have the dominant influence in the ground recovery phase as the borehole thermal resistance is equal to zero. One can notice that the temperature steadiness is reached at $5 \mathrm{~m}$ depth sooner than in other layers, attributed to the influence of the aquifer and increased thermal 
diffusivity. The quasi-stationary heat exchange is achieved between 200 and $300 \mathrm{~h}$ after the TRT process is finished. Perturbation of temperatures shortly before $400^{\text {th }}$ hour is a result of an undisturbed ground temperature measurement with the GEOgert 2.0 unit.

Figure 7 represents the derivative curve of ground temperature decrease in time after the TRT, temperature difference recorded is divided by 2.5 minute intervals. Data from the last five days of the recovery period are presented with red circles and data is approximated with a line. As the ground cools down the temperature asymptotically approaches the undisturbed state. Javed et al [18] suggested that temperature difference of $0.3{ }^{\circ} \mathrm{C}$ can be used as acceptable value to recommence the TRT procedure in case of multiple measurements on same location. After 24 days of recovery the average ground temperature along the depth, omitting the first $10 \mathrm{~m}$, was $0.3{ }^{\circ} \mathrm{C}$ from the measured undisturbed temperature.

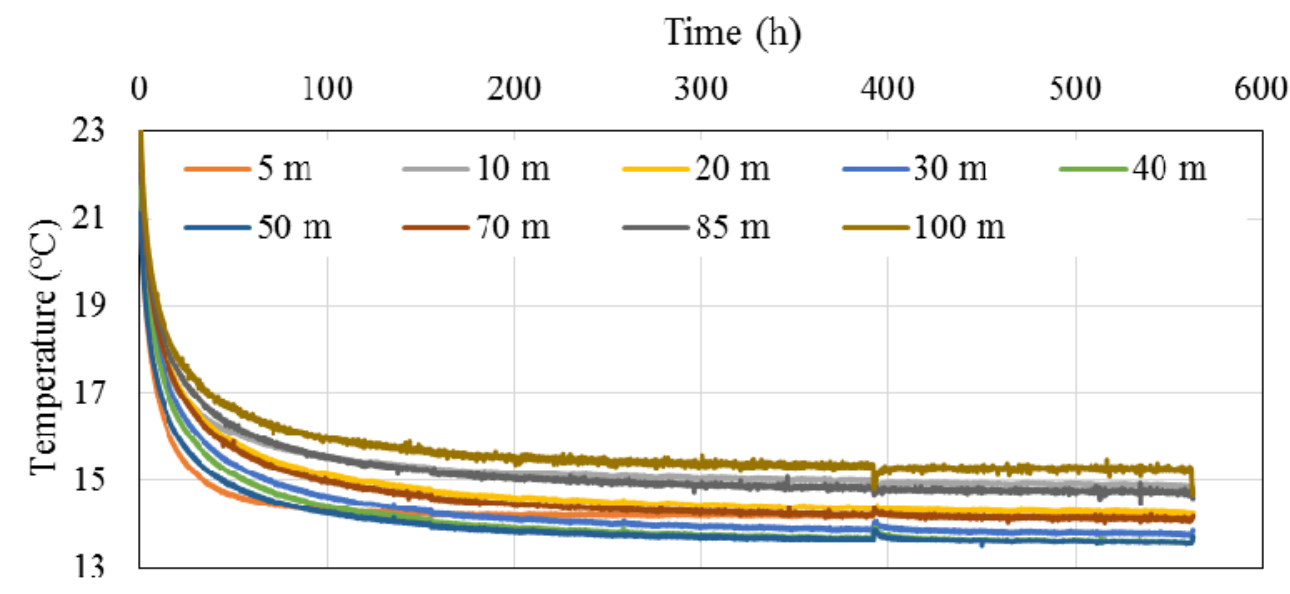

Fig. 6 The ground recovery profiles after the first TRT

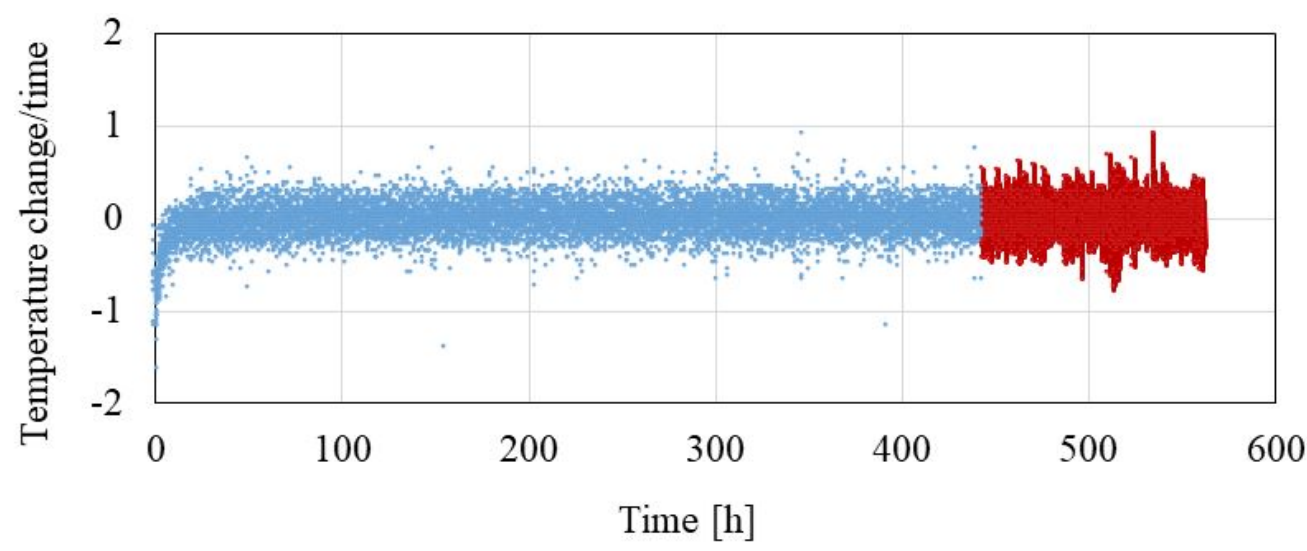

Fig. 7 Average borehole temperature change versus time during recovery, time is expressed as the time after end of TRT circulation

\subsection{The second TRT measurement}

The TRT measurement duration is $72 \mathrm{~h}$ with the parameters as follows:

- the average heating power

$7.64 \mathrm{~kW}$

- the average flow rate

- the average undisturbed ground temperature (thermocouples)

$14.2{ }^{\circ} \mathrm{C}$

Figure 8 shows the ground temperature at various depths in different time instances of the second TRT measurement. The Figures 5 and 8 are qualitatively equal, but the differences are in time- and depth-dependent temperatures. The temperatures recorded are up to $10{ }^{\circ} \mathrm{C}$ higher than in the first TRT. 
Estimation of days needed for the ground to recover is displayed on Figure 9. Estimation is based on the last measured ground temperature and $0.02{ }^{\circ} \mathrm{C} /$ day rate of temperature change that was established from temperature profiles on Figure 6. As already mentioned, due to asymptotic nature of temperature evolution this is only a rough estimate.

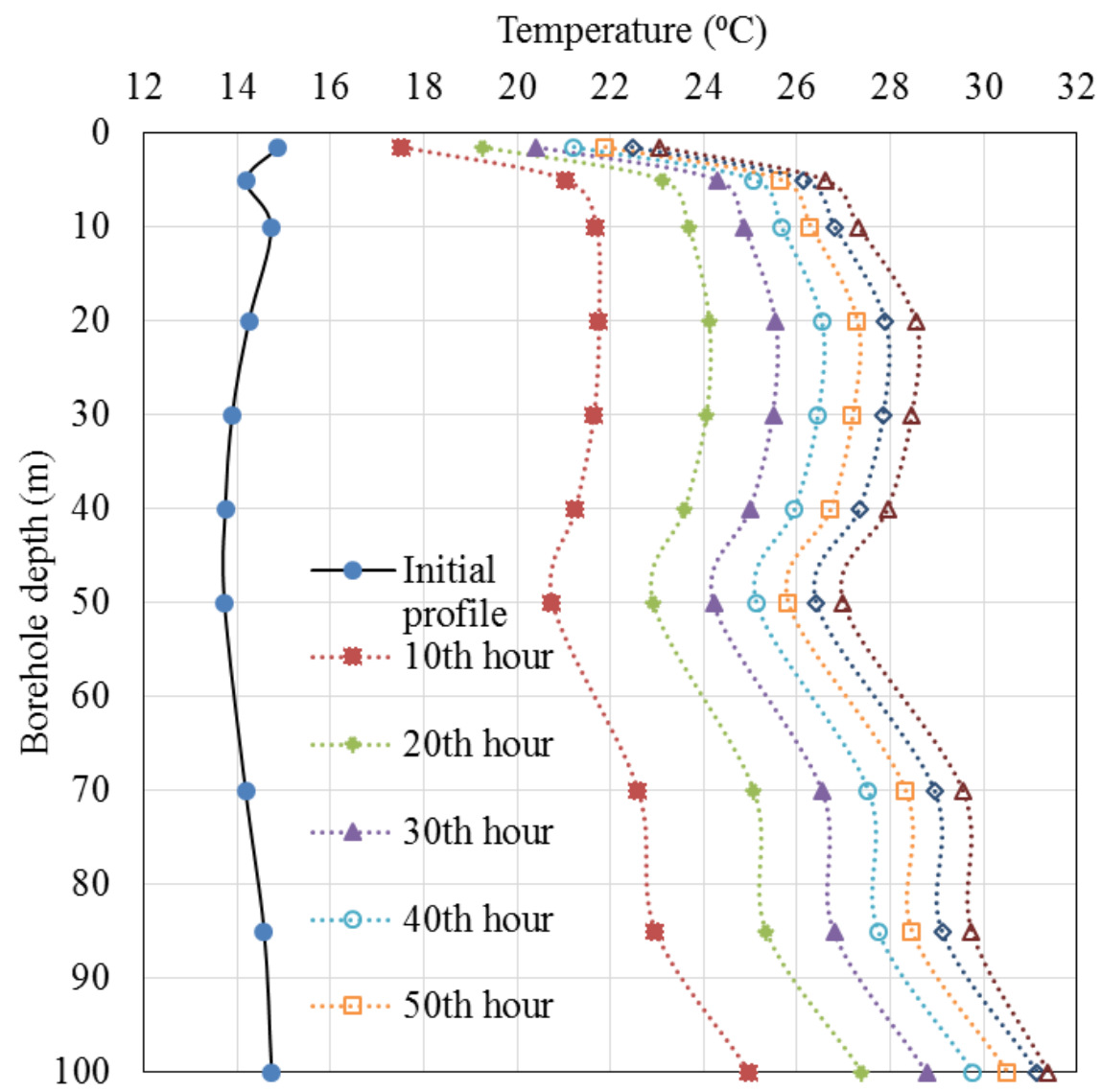

Fig. 8 The ground temperature profiles during the second TRT measurement (7.6 kW) (15.-18. April 2016.)

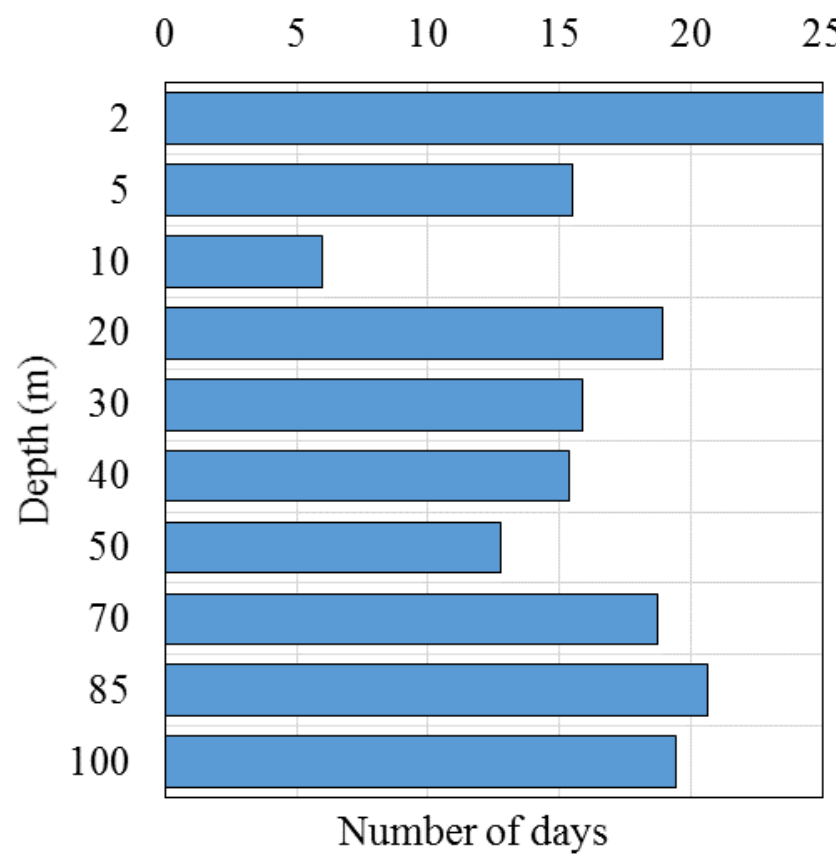

Fig. 9 Estimated time needed for full ground recovery 


\section{Comparison of TRT's and discussion}

The change in fluid inlet and outlet temperature is depicted in Figures 10 and 11. In the first hours of the measurement, one can notice the unsteady temperature change. This temperature evolution is caused by the insufficient warm-up of the pipes, the borehole filling and the other components that take part in heat transfer process. In first $16 \mathrm{~h}$ of the first TRT measurement, the outlet BHE fluid temperature change is $7.4{ }^{\circ} \mathrm{C}$, while the temperature change in the remaining 56 hours is $3.5^{\circ} \mathrm{C}$. The slower temperature change after $16^{\text {th }}$ hour is a consequence of borehole warm-up and dominant influence of the ground properties on the heat exchange process. The BHE inlet temperature in the last hour of measurement is $27.9^{\circ} \mathrm{C}$ while the outlet temperature is $24.7^{\circ} \mathrm{C}$. In first $16 \mathrm{~h}$ of the second TRT measurement, the inlet temperature change is $12.8{ }^{\circ} \mathrm{C}$, while in the remaining $56 \mathrm{~h}$ the temperature change is $5.1{ }^{\circ} \mathrm{C}$. Final recorded temperatures are $38.1{ }^{\circ} \mathrm{C}$ at the inlet and $32.6^{\circ} \mathrm{C}$ at the outlet.

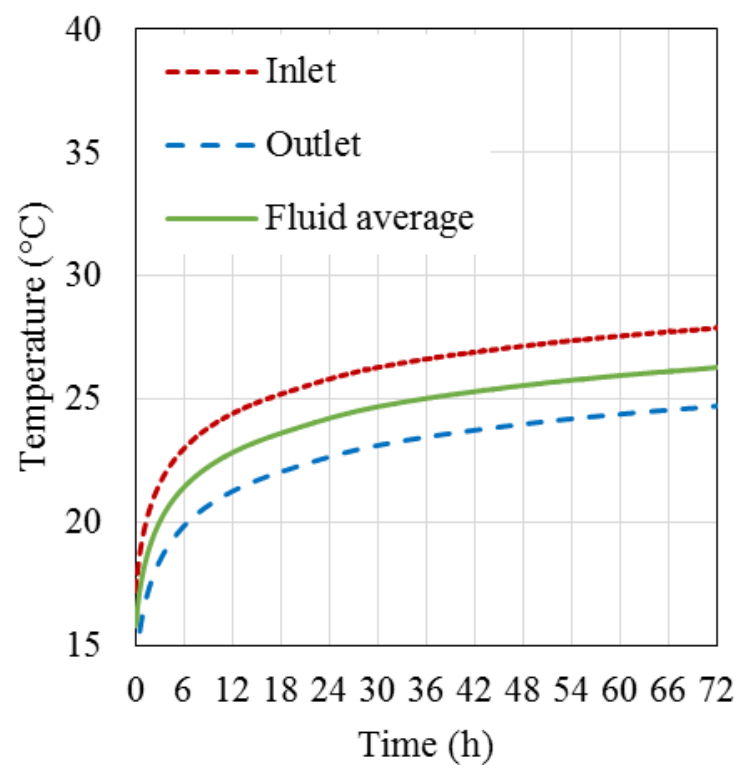

Fig. 10 Fluid temperature evolution, TRT I

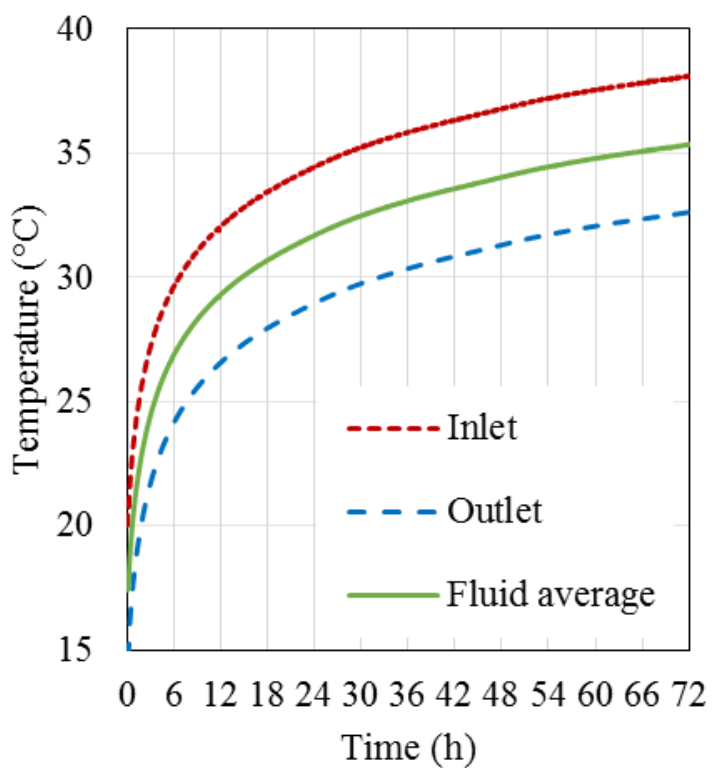

Fig. 11 Fluid temperature evolution, TRT II

On the other hand, Figure 12 and 13 show change in BHE inlet and outlet temperatures as a function of time in a semi-log fashion. The part which is taken into consideration for computation of effective ground heat conductivity and borehole heat resistance is outlined in Figures 12 and 13. The measurement data obtained within a period from $11^{\text {th }}$ to $72^{\text {nd }}$ hour are analyzed. Equation 1 represents Infinite Line Source model and it is used on data after first 11 $\mathrm{h}$ are omitted according to the time criterion (equation $2, r_{b}=152 \mathrm{~mm}$ and $\alpha=3 \cdot 10^{-6} \mathrm{~m}^{2} / \mathrm{s}$ ) [10]. Equations 3 and 4 are final expressions used to extract effective ground thermal properties after linearization of equation 1. Symbols used: $q$ is specific heat flux in $\mathrm{W} / \mathrm{m}, \lambda$ is ground thermal conductivity), $t$ is time in seconds, $\gamma$ is Euler number, $r_{b}$ is borehole radius, $\vartheta_{f}$ and $\vartheta_{0}$ are fluid and ground temperature, $\alpha$ is thermal diffusivity, $R_{b}$ is borehole thermal resistance and $k$ is inclination presented in Figures 12 and 13.

$$
\begin{aligned}
& \vartheta_{f}(t)=\frac{q}{4 \lambda \pi}\left(\ln \left(\frac{4 \alpha t}{r^{2}}\right)-\gamma\right)+q R_{b}+\vartheta_{0} \\
& t_{b}=5 r_{b}^{2} / \alpha \\
& \lambda=q /(4 \pi k) \\
& R_{b}=\frac{\vartheta_{f}-\vartheta_{0}}{q}-\frac{1}{4 \pi \lambda}\left(\ln (t)+\ln \left(\frac{4 \alpha}{r^{2}}\right)-\gamma\right)
\end{aligned}
$$


The line inclination is directly connected with the intensity of the heat flux. The line inclination in the second measurement is 3.4, while in the first measurement is 1.96. Standard ILS procedure is used to determine thermal conductivity and borehole thermal resistance and results are listed in Table $1[3,4]$.

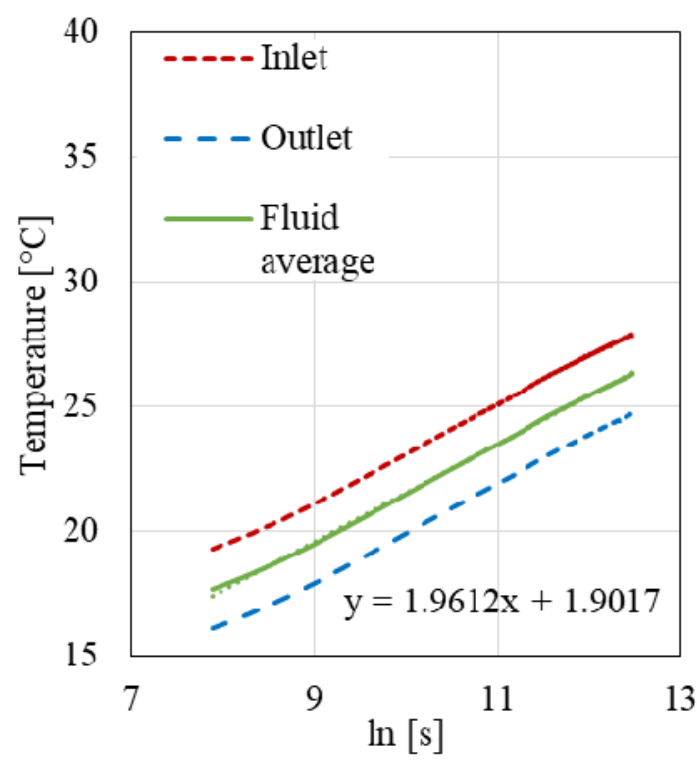

Fig. 12 The change in fluid temperature as function of logarithmic time, TRT I

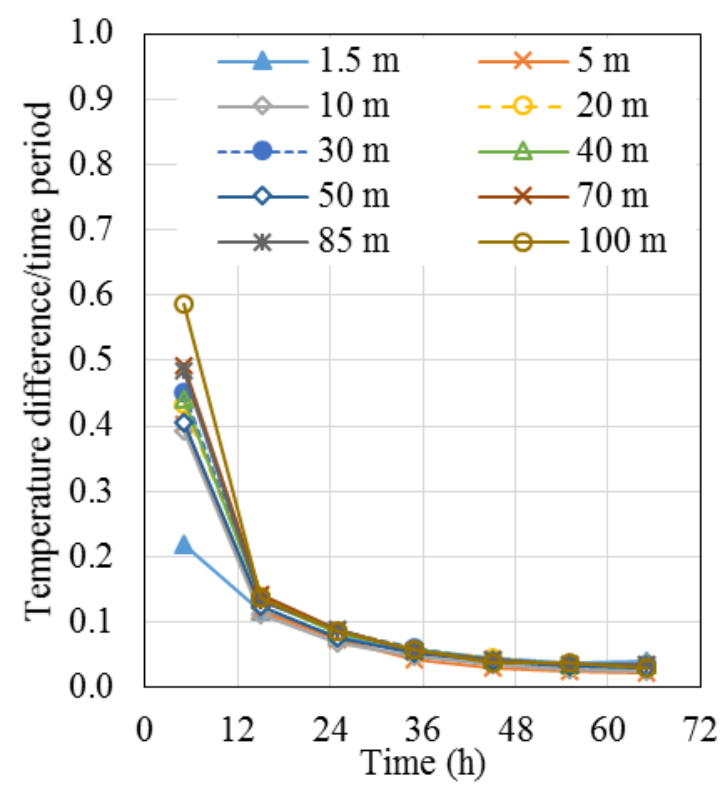

Fig. 14 The rate of change of fluid temperature in time, TRT I

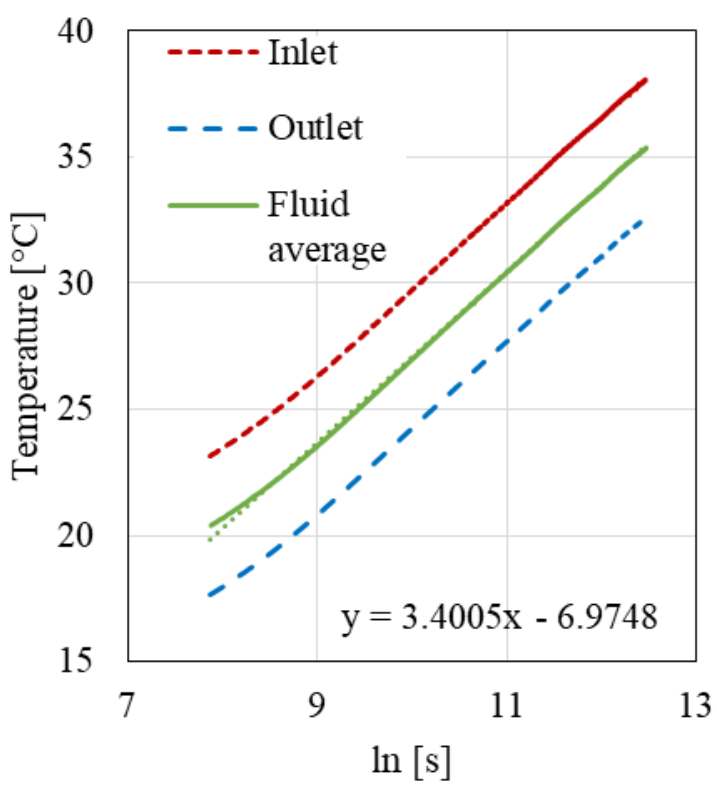

Fig. 13 The change in fluid temperature as function of logarithmic time, TRT II

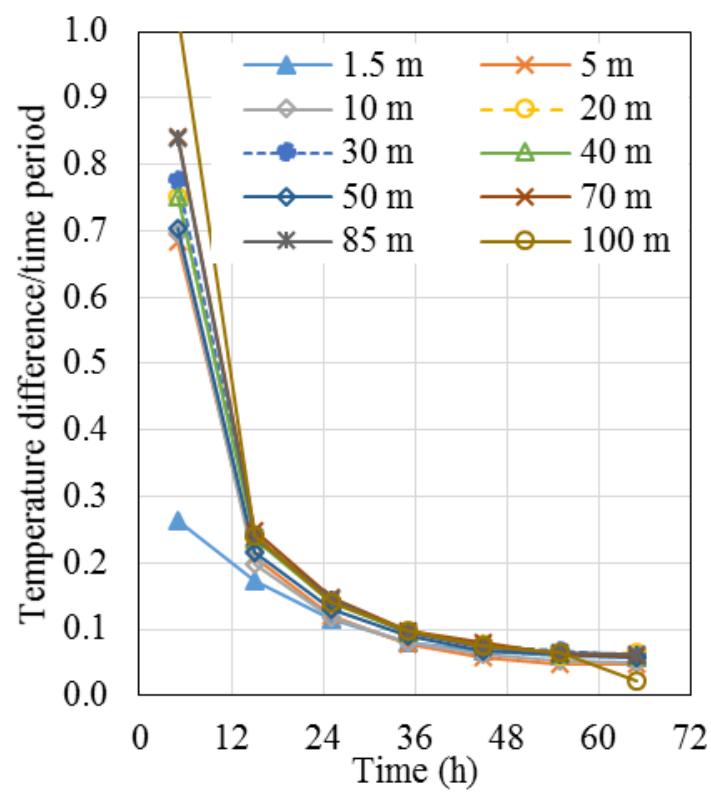

Fig. 15 The rate of change of fluid temperature in time, TRT II

Temperature curves from figures 12 and 13 are used to calculate the rate of temperature change over time. Since the data was collected on hourly time scale and derivative curve requires time step of no more than few minutes, simple difference of temperature over time difference was used to produce the figures. On Figures 14 and 15, temperature increase is divided by time period of 10 hours and resulting value is appointed to average hour in time period. Clearly, the stable temperature increase is reached faster with the smaller heat flux applied. 
Step analysis was used to obtain the heat conductivity curve in time (displayed in Figure 16). For each step same starting point of $11^{\text {th }}$ hour was used, while ending hour of data interval was increased by 5 hours in every step. Thermal conductivity was than calculated for different time intervals by including more data with every new calculation. Variation of calculated values in first 30-40 hours shows that TRT should last at least 48 hours as it is mostly recommended in literature. Increasing value of effective ground conductivity with time indicates the existence of groundwater [16]. Therefore, prolongation of TRT might lead to higher and wrong values of thermal conductivity if step analysis is not used to check the data obtained. In Figure 16, one can notice that the variation in ground thermal conductivity is less affected in the TRT where the higher heat flux was used. Between $46^{\text {th }}$ and $51^{\text {st }}$ hour of TRT, difference of thermal conductivity is $0.3 \%$ approximately, while at the $71^{\text {st }}$ hour difference is $2 \%$. Larger difference in the results is noticeable for the borehole thermal resistance. Since the borehole thermal resistance calculation is based on the undisturbed ground temperature, incomplete recovery after TRT I stop can be the cause for the larger difference.

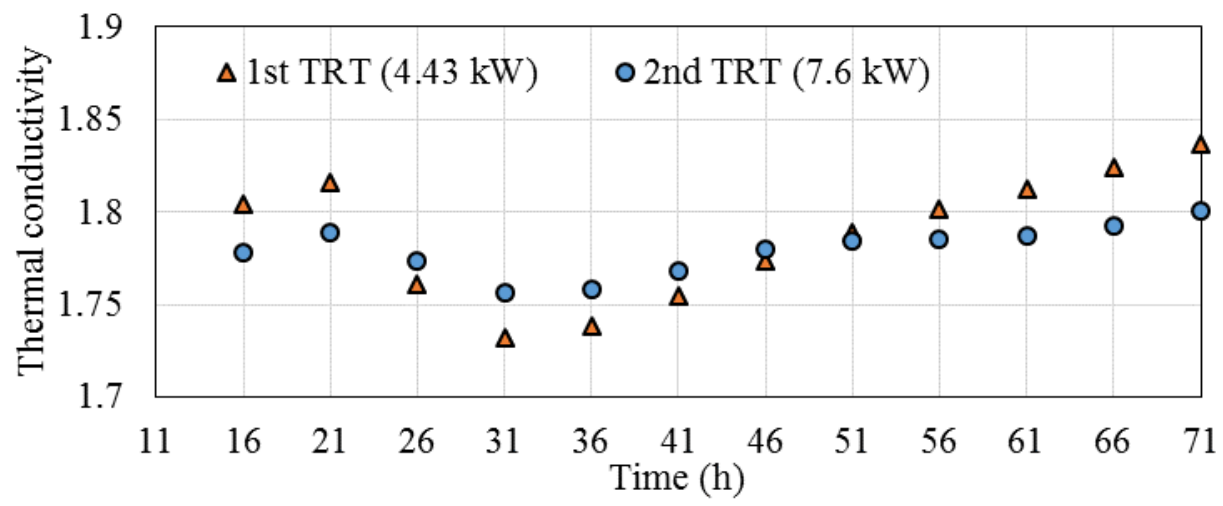

Fig. 16 The step change in ground thermal conductivity at later times indicates the existence of convective heat transfer

The values of effective heat conductivity of the ground and the borehole thermal resistance are listed in Table 1.

Table 1 The results of the performed TRT measurements (from $46^{\text {th }}$ to $51^{\text {st }}$ hour of TRT)

\begin{tabular}{|c|c|c|}
\hline & TRT I & TRT II \\
\hline Average heat flux supplied to fluid $\Phi(\mathrm{kW})$ & 4.43 & 7.64 \\
\hline Initial ground temperature $T_{0}\left({ }^{\circ} \mathrm{C}\right)$ & 13.97 & 14.23 \\
\hline Effective ground thermal conductivity $\lambda_{e f}, \mathrm{~W} /(\mathrm{m} \cdot \mathrm{K})$ & 1.789 & 1.784 \\
\hline Effective BHE thermal resistance $R_{e f},(\mathrm{~m} \cdot \mathrm{K}) / \mathrm{W}$ & 0.069 & 0.064 \\
\hline Average effective ground thermal conductivity $\overline{\lambda_{e f}}, \mathrm{~W} /(\mathrm{m} \cdot \mathrm{K})$ & \multicolumn{2}{|c|}{1.787} \\
\hline Average effective BHE thermal resistance $\overline{R_{b, 8 f}},(\mathrm{~m} \cdot \mathrm{K}) / \mathrm{W}$ & \multicolumn{2}{|c|}{0.067} \\
\hline
\end{tabular}




\section{Conclusion}

In the scope of this research, two TRT measurements were carried out, each of 72 hours duration, with different average injected heat fluxes $(4.43$ and $7.64 \mathrm{~kW})$. The average ground heat conductivity is determined to be $1.787 \mathrm{~W} /(\mathrm{m} \cdot \mathrm{K})$, while the average borehole thermal resistance is $0.067(\mathrm{~m} \cdot \mathrm{K}) / \mathrm{W}$.

From the results presented, it can be conclude that:

- there is no significant difference in the results obtained by applying the two different heat fluxes, but step analysis must be conducted to evaluate the variation of thermal properties in time

- the lower thermal resistance obtained in the second TRT measurement could be partially attributed to the ground not being fully recovered

- ground recovery is a slow and asymptotic process; acceptable temperature difference from the undisturbed state should be used if multiple TRT's are planned to be conducted on the same borehole

- application of higher heat flux minimizes the influence of the non-homogeneous ground structure and groundwater

- conduction of TRT and the application of the appropriate methodology is the only way to determine the effective properties required for borehole field dimensioning; still care should be taken to eliminate possible errors in the measurement and calculation procedures.

\section{Acknowledgements}

The authors are most grateful to reviewers whose insightful comments led to the improvement of the original manuscript.

\section{REFERENCES}

[1] Yang, H., Cui, P., Fang, Z.: Vertical-borehole ground-coupled heat pumps: A review of models and systems, Appl. Energy, 87 (2010), 16-27. https://doi.org/10.1016/j.apenergy.2009.04.038

[2] Beier, R., Acuña, J., Mogensen, P., Palm, B.: Borehole resistance and vertical temperature profiles in coaxial borehole heat exchangers, Appl. Energy, 102 (2013), 665-675. https://doi.org/10.1016/j.apenergy.2012.08.007

[3] Luo, J., Rohn, J., Xiang, W., Bertermann, D., Blum, P.: A review of ground investigations for ground source heat pump (GSHP) systems, Energy Build., 117 (2016), 160-75. https://doi.org/10.1016/j.enbuild.2016.02.038

[4] Zhang, C., Guo, Z., Liu, Y., Cong, X., Peng, D.: A review on thermal response test of ground-coupled heat pump systems, Renew. Sustain. Energy Rev., 40 (2014), 851-67. https://doi.org/10.1016/j.rser.2014.08.018

[5] Esen, H., Inalli, M., Esen, Y.: Temperature distributions in boreholes of a vertical ground-coupled heat pump system, Renew. Energy., 34 (2009), 2672-9. https://doi.org/10.1016/j.renene.2009.04.032

[6] Signorelli, S., Bassetti, S., Pahud, D., Kohl, T.: Numerical evaluation of thermal response tests, Geothermics, 36 (2007) 141-166. https://doi.org/10.1016/j.geothermics.2006.10.006

[7] Marcotte, D., Pasquier, P.: On the estimation of thermal resistance in borehole thermal conductivity test, Renew. Energy., 33 (2008), 2407-15. https://doi.org/10.1016/j.renene.2008.01.021

[8] Lamarche, L., Kajl, S., Beauchamp, B.:A review of methods to evaluate borehole thermal resistances in geothermal heat-pump systems, Geothermics, 39 (2010)187-200. https://doi.org/10.1016/j.geothermics.2010.03.003

[9] Soldo, V., Borovic, S., Leposa, L., Boban, L.: Comparison of different methods for ground thermal properties determination in a clastic sedimentary environment, Geothermics, 61 (2016), 1-11. https://doi.org/10.1016/j.geothermics.2015.12.010

[10] Carslaw, H. S., Jaeger, J. C.: Conduction of Heat in Solids, 2nd edition, Oxford: Clarendon Press, 1959. 
L. Boban, V. Soldo, J. Stošić,

E. Filipović, F. Tremac
Ground Thermal Response and Recovery after Heat Injection: Experimental Investigation

[11] Spitler, J. D., Gehlin, S. E.: Thermal response testing for ground source heat pump systems-An historical review, Renew. Sustain. Energy Rev., 50 (2015), 1125-37. https://doi.org/10.1016/j.rser.2015.05.061

[12] Sanner, B., Hellström, G., Spitler, J. D., Gehlin, S.: More than 15 years of mobile Thermal Response Test - a summary of experiences and prospects, European Geothermal Congress 2013, Pisa, Italy, 2013

[13] Soldo, V., Boban, L., Borović, S.; Vertical distribution of shallow ground thermal properties in different geological settings in Croatia, Renewable Energy 99 1202-1212 (2016). https://doi.org/10.1016/j.renene.2016.08.022

[14] Fujii, H., Okubo, H., Nishi, K., Itoi, R., Ohyam, K., Shibata, K.: An improved thermal response test for U-tube ground heat exchanger based on optical fiber thermometers, Geothermics 38, 2009. https://doi.org/10.1016/j.geothermics.2009.06.002

[15] Soldo, V., Ruševljan, M., Ćurko, T.: Test geothermal heat pump with a $100 \mathrm{~m}$ deep borehole heat exchanger, Klima forum Zadar, Croatia, 2009.

[16] Katsura, T., Nagano, K., Takeda, S., Shimakura, K.: Heat transfer experiment in the ground with ground water advection, The IEA 10th Energy Conservation Thermal Energy Storage Conference, New Jersey, USA, 2006.

[17] Rybach L., Bayer, P., Rivera, J., Blum, P.: Influence factors in the depth domain of borehole heat exchangers - global warming and urban heating. Proceedings of European Geothermal Congress 2016, Strasbourg, France, 2016

[18] Javed, S., Claesson, J., Beier, R.: Recovery times after thermal response tests on vertical borehole heat exchanger, Proceedings of $23^{\text {rd }}$ IIR International Congress of Refrigeration, Prague, Czech Republic, 2011.

Submitted: $\quad$ 14.6.2017

Accepted: $\quad 15.02 .2018$
Luka Boban

Vladimir Soldo

Jure Stošić

Eugen Filipović

Filip Tremac

Faculty of Mechanical Engineering and

Naval Architecture University of Zagreb,

Ivana Lučića 5, Zagreb, Croatia

luka.boban@fsb.hr 